\title{
Energy Requirement and Food Intake Behaviour in Young Adult Intact Male Cats with and without Predisposition to Overweight
}

\author{
Brigitta Wichert, ${ }^{1}$ Julia Trossen,, ${ }^{1}$ Daniel Uebelhart, ${ }^{2}$ Marcel Wanner, ${ }^{1}$ and Sonja Hartnack ${ }^{3}$ \\ ${ }^{1}$ Institute of Animal Nutrition, Vetsuisse Faculty, University of Zurich, Winterthurerstraße 260, 8057 Zurich, Switzerland \\ ${ }^{2}$ Department of Rheumatology and Institute of Physical Medicine, University Hospital Zurich, Gloriastraße 25, \\ 8091 Zurich, Switzerland \\ ${ }^{3}$ Section of Epidemiology, Vetsuisse Faculty, University of Zurich, Winterthurerstraße 270, 8057 Zurich, Switzerland \\ Correspondence should be addressed to Brigitta Wichert, bwichert@vetphys.uzh.ch
}

Received 31 October 2011; Accepted 25 December 2011

Academic Editor: Anna Brzozowska

Copyright ( $) 2012$ Brigitta Wichert et al. This is an open access article distributed under the Creative Commons Attribution License, which permits unrestricted use, distribution, and reproduction in any medium, provided the original work is properly cited.

\begin{abstract}
Obesity is a common problem in cats. In the experimental cat family of the institute of animal nutrition besides a "normal" lean phenotype, cats with predisposition to an overweight phenotype are present. To investigate energy requirements and food intake behaviour of intact male cats of different phenotypes, six "normal" lean cats (GL) and six cats disposed to overweight (GO) were used. At the beginning of the experiment, all cats had an ideal body condition score of 5 . To reach this the GO cats had to pass a weight-loss program. Energy requirements of the cats were determined using respiration chambers, whereas the amount and frequency of food intake was measured with a feeding station recording the data automatically. Energy requirement at weight constancy of the GO cats was even on fat-free mass (FFM) significantly $(P=0.02)$ lower $(162.6 \mathrm{~kJ} / \mathrm{kg} \mathrm{FFM} / \mathrm{d})$ than that of the "normal" lean cats $(246 \mathrm{~kJ} / \mathrm{kg} \mathrm{FFM} / \mathrm{d})$. The GO cats also showed a higher food intake $34.5 \pm 1.5 \mathrm{~g}$ dry matter $/ \mathrm{kg}$ body weight ${ }^{0.67}$ compared to the GL cats $\left(24.0 \pm 2.1 \mathrm{~g}\right.$ dry matter $/ \mathrm{kg}$ body weight $\left.{ }^{0.67}\right)(P=0.001)$. In conclusion quantifiable differences in food intake and behaviour in cats predisposed to overweight compared to "normal" lean cats were found.
\end{abstract}

\section{Introduction}

Obesity is an increasing problem in cats. In recent studies, the prevalence of feline obesity in different countries has ranged from $6 \%$ to $52 \%[1,2]$. Obesity is the result of a higher energy intake in comparison to the energy requirement. This can be caused by an increased energy intake, decreased energy expenditure, or both. Multiple factors like castration, highly palatable food, cats keeping indoors, and genetic factors are related to obesity [2-4]. In several human and rodent studies, a genetic background was supported [5-7]. Recently also in cats a genetic association with overweight has been described in the experimental cat population of the Institute of Animal Nutrition of the Vetsuisse Faculty of Zurich [8]. However, to our knowledge, nothing is known about energy expenditure or food intake behaviour of intact cats developing overweight. An increase in food intake can be due to a higher meal frequency or a higher food intake per meal. The cat as a hunter of small prey animals has to eat about twelve small prey animals, corresponding to twelve meals in 24 hours [9]. A similar meal frequency of about 1220 meals per day was observed in the studies of Mugford and Thorne [10], Kane et al. [11], and Peachey and Harper [12]. However, Horwitz et al. [13] described that meal size was influenced by daytime as well as palatability and protein content of food. In contrast to this, the speed of food intake was more connected to food structure.

The aim of the present study was to quantify the difference in energy expenditure or food intake behaviour in intact male cats with and without predisposition to overweight.

\section{Material and Methods}

2.1. Cats. The study population consisted of six intact male cats displaying a phenotype lean (group GL) and six intact male cats with a phenotype overweight (group GO) aged $1.3 \pm 0.06$ years. Classification into phenotype lean/overweight was based on body condition score (BCS) measured 


\begin{tabular}{l|c|c|c|c|c|}
\hline Adaptation & $\begin{array}{c}\text { Respiration } \\
\text { chambers }\end{array}$ & $\begin{array}{c}\text { Ad libitum } \\
\text { feeding I }\end{array}$ & $\begin{array}{c}\text { Data collection } \\
\text { food intake }\end{array}$ & $\begin{array}{c}\text { Ad } \\
\text { libitum } \\
\text { feeding II }\end{array}$ \\
\hline 7 days & 4 days & 58 days & 14 days & $X$ days \\
\hline & & & & \\
\hline & 8 & 12 & 70 & 84 & $84+X$ \\
$\begin{array}{l}\uparrow \\
\text { DEXA I }\end{array}$ & & & & $\uparrow$ \\
DEXA II
\end{tabular}

Figure 1: Experimental study design of the five experimental phases including measurements in the respiration chambers, measurements of food intake as well as dual energy X-ray absorptiometry measurements.

TABLE 1: Chemical composition (\%) of the commercial dry cat food used during the whole experiment.

\begin{tabular}{lc}
\hline Ingredients & Content \\
\hline Crude protein & $32 \%$ \\
Crude fat & $21 \%$ \\
Crude fiber & $2 \%$ \\
Crude ash & $6 \%$ \\
Nitrogen-free extracts & $31 \%$ \\
Dry matter & $92 \%$ \\
Gross energy & $22.9 \mathrm{~kJ}$ \\
\hline
\end{tabular}

at month eight according to Laflamme [14]. All cats were reared under the same conditions, clinically healthy, and intact male European Shorthair cats. They originated from a larger breeding project with a focus on segregation of lean and overweight phenotypes in the cat-breeding family of the Institute of Animal Nutrition at the Vetsuisse Faculty, Zurich [8]. Ethical approval for animal experimentation was obtained from the Swiss veterinary authorities (license number 180/2009).

2.2. Study Design. The experimental study design comprised five different phases (Figure 1). Before starting the experiment, all cats of group GO passed through a weight loss program until reaching a BCS of 5. After that the cats of group GO were fed to maintain a constant body weight (BW) for at least 4 weeks. The cats of group GL were fed ad libitum during the whole experiment.

2.2.1. Adaptation Period (Duration 7 Days). The cats of group GO were fed to maintain a constant bodyweight (BW). During the adaptation period, cats were adapted to a commercial dry cat food (Table 1) and special cat toilettes allowing for separate collection of faeces and urine [15].

\subsubsection{Respiration Chamber Period (Duration 5 Days). Cats} were kept individually for 22.5 hours per day in the respiration chambers $(1.4 \mathrm{~m} \times 1.0 \mathrm{~m} \times 0.9 \mathrm{~m})$. After one day for adaptation, on a daily basis, $\mathrm{O}_{2}$ consumption and $\mathrm{CO}_{2}$ production were determined with reference to body weight, body weight ${ }^{0.67}$, and fat-free mass [16]. On a daily basis,

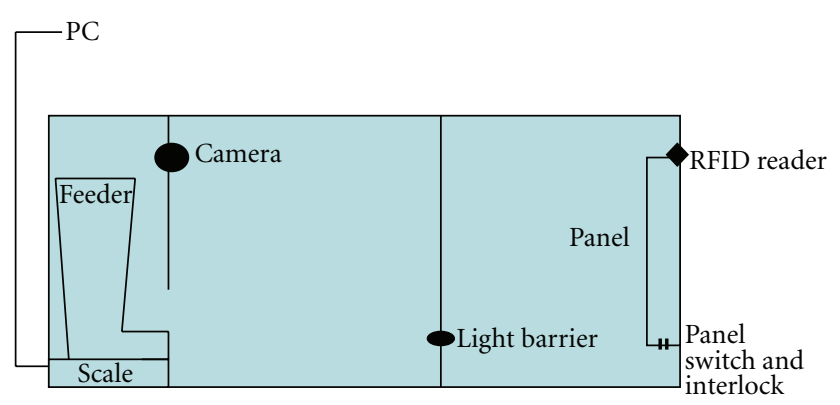

FIGURE 2: Design of the automatically cat food station: documenting food intake per meal, meal frequency, visits of the station without eating, and the time of entering the station. The cats were recognized by their implanted microchip.

faeces and urine were collected separately, and food intake was measured. From these data nitrogen, carbon and energy balances were calculated.

An equalized energy balance at weight constancy is named energy requirement in the text although energy consumption in respiration chambers mostly is lower compared to that under usual living conditions, as activity is limited.

2.2.3. Ad Libitum Feeding Phase I (Duration 58 Days). During this period cats were kept in groups of two cats each in an indoor-outdoor enclosure.

2.2.4. Automatic Food Station Phase (Duration 14 Days). During this phase, food intake per meal, frequency of meals, visits of the station without eating, and the time of entering the station were recorded. The intake of metabolisable energy (ME) was calculated using the ME-content of the dry food determined during the respiration measurement. Additionally, each action of the cats was documented using a camera. The automatic feeding station (Figure 2) recognized the cats by their implanted chip and assured that there was only one cat each inside the station with help of a light barrier that recognized movements in the feeding station. For the function of the feeding station as well as the documentation of the data, special software was developed (Gruber Informatik AG, Bergdietikon, Switzerland).

\subsubsection{Ad Libitum Feeding Phase II (Duration Variable; Min} 4 Weeks, Max 27 Weeks). During this period two cats were kept together in an indoor-outdoor enclosure and fed until a constant body weight was obtained for at least four weeks.

\subsection{Measurements and Analysis}

2.3.1. Body Weight and Body Fat. During the measurements in the respiration chamber, the cats were weighed daily, during other phases weekly. As shown in Figure 1, before respiration measurements and at the end of the second ad libitum feeding phase after four weeks of weight constancy, body fat content and lean body mass (=fat-free mass (FFM)) were determined by dual X-ray absorptiometry (DEXA). 
TABLE 2: Mean of body weight (BW), body fat mass (total (g), and (\%)) fat-free body mass (total (g), and (\%)) and body weight (g) of the cats of the groups GL (lean phenotype) and GO (overweight phenotype); DEXA I: first DEXA measurement before the adaptation period; DEXA II: second DEXA measurement at the end of the second phase of ad libitum feeding after four weeks of weight constancy.

\begin{tabular}{|c|c|c|c|c|}
\hline & \multicolumn{2}{|c|}{ GL } & \multicolumn{2}{|c|}{$\mathrm{GO}$} \\
\hline & DEXA I & DEXA II & DEXA I & DEXA II \\
\hline Body weight \pm SE $(\mathrm{g})$ & $5063 \pm 251^{\text {aA }}$ & $4992 \pm 267^{\mathrm{aA}}$ & $5036 \pm 261^{\mathrm{aA}}$ & $6487 \pm 324^{\mathrm{bB}}$ \\
\hline Fat mass $\pm \mathrm{SE}(\mathrm{g})$ & $380 \pm 51^{\mathrm{aA}}$ & $336 \pm 81^{\mathrm{aA}}$ & $199 \pm 39^{\mathrm{aB}}$ & $893 \pm 94^{\mathrm{bB}}$ \\
\hline Fat mass $\pm \mathrm{SE}(\%)$ & $7 \pm 1^{\mathrm{aA}}$ & $7 \pm 1^{\mathrm{aA}}$ & $5 \pm 1^{\mathrm{aB}}$ & $14 \pm 1^{\mathrm{bB}}$ \\
\hline Fat free mass $\pm \mathrm{SE}(\mathrm{g})$ & $4543.0 \pm 214.4^{\mathrm{aA}}$ & $4656.2 \pm 196.9^{\mathrm{aA}}$ & $\begin{array}{l}4768.8 \pm \\
262.2^{\mathrm{aA}}\end{array}$ & $5429.7 \pm 251.6^{\mathrm{bB}}$ \\
\hline Fat free mass \pm SE $(\%)$ & $89.8 \pm 0.8^{\mathrm{aA}}$ & $90.7 \pm 1.4^{\mathrm{aA}}$ & $92.0 \pm 0.8^{\mathrm{aB}}$ & $83.8 \pm 1.0^{\mathrm{bB}}$ \\
\hline
\end{tabular}

Different letters show significant differences $(P<0.05)$, capital letters show group differences, whereas small letters show differences within one group.

TABle 3: Differences between both phenotypes estimated with a linear mixed model approach (group means and standard errors of the estimated effect due to phenotype; GL: lean phenotype, GO: overweight phenotype).

\begin{tabular}{|c|c|c|c|c|}
\hline & $\begin{array}{c}\text { Phenotype GL } \\
\text { mean }\end{array}$ & $\begin{array}{c}\text { Phenotype GO } \\
\text { mean }\end{array}$ & S.E. & $P$ value \\
\hline $\mathrm{O}_{2} \mathrm{~L} / \mathrm{kg} \mathrm{BW} W^{0.67} / \mathrm{d}$ & 19.67 & 17.31 & 1.05 & 0.026 \\
\hline $\mathrm{O}_{2} \mathrm{~L} / \mathrm{kg} \mathrm{BW} / \mathrm{d}$ & 11.71 & 10.26 & 0.64 & 0.035 \\
\hline $\mathrm{O}_{2} \mathrm{~L} / \mathrm{kg} \mathrm{FFM} / \mathrm{d}$ & 12.88 & 10.87 & 0.8 & 0.022 \\
\hline $\mathrm{CO}_{2} \mathrm{~L} / \mathrm{kg} \mathrm{BW}{ }^{0.67} / \mathrm{d}$ & 16.66 & 14.75 & 0.64 & 0.008 \\
\hline $\mathrm{CO}_{2} \mathrm{~L} / \mathrm{kg} \mathrm{BW} / \mathrm{d}$ & 9.59 & 8.74 & 0.4 & 0.046 \\
\hline $\mathrm{CO}_{2} \mathrm{~L} / \mathrm{kg} \mathrm{FFM} / \mathrm{d}$ & 10.57 & 9.25 & 0.46 & 0.01 \\
\hline
\end{tabular}

For the DEXA measurement in the sternal recumbency, a Hologic QDR 4500 Discovery machine (Bedford, MA, USA) was used. QDR System software Version 12.4 and the Infant Whole Body scan type were used. The machine's lower body fat-measuring limit was approximately 4\%. For data analyses, the global mode (includes the whole body with extremities and head) was used. The cats were sedated with medetomidine $0.05 \mathrm{mg} / \mathrm{kg} \mathrm{BW}$ and butorphanol $0.2 \mathrm{mg} / \mathrm{kg}$ BW.

2.3.2. Statistical Analyses. The objective of the statistical analysis was to test the hypothesis of difference in "normal" lean cats and cats predisposed to overweight. For comparisons between two groups at the same time point or two time points within the same group, non-parametric tests (Wilcoxon rank sum and Wilcoxon signed rank) were performed with the software NCSS 2007 version 7.1.20 (Kaysville, Utah, USA). Statistical significance was set at $P \leq 0.05$. To estimate a potential effect of phenotype overweight versus lean during repeated measurements in the respiration chamber, linear and linear mixed effects models were used with the software $\mathrm{R}$ version 2.11.1 [17] and the packages nlme [18] and lmtest [19]. $P$ values for linear models were derived from likelihood ratio tests. In order to account for potential correlation of measurements within cats, cat was used as random effect. Model selection was based on (AIC Akaike's information criterion) with a lower AIC indicating a better model fit and visual checking of the random effects residuals. Highly influential or leverage data points were determined using Cook's distance. Results are given in marginal means of effect sizes and their corresponding standard errors (S.E.).

\section{Results}

3.1. Body Weight and Fat Content. At the beginning of the adaptation period, there was no statistical difference in body weight between groups, but in body fat content (fat mass in $g$ $P=0.02$, fat mass in $\% P=0.03$ ) with group GO having a lower fat content (Table 2). Statistical differences between both groups were found at the end of the second ad libitum phase, with the group GO having a statistically significant higher body weight $(P=0.013)$ and body fat content (fat mass in $\mathrm{g} P=0.005$, fat mass in $\% P=0.005$ ) compared to group GL. Whereas the measurements in group GL did not differ significantly in between the first and the second measurement, in group GO statistical significant differences were found (body weight $P=0.02$, body fat mass in $\mathrm{g}$ $P=0.005$, body fat mass in $\% P=0.005)$.

3.2. Respiration Measurements. Using a linear mixed model approach, significant differences in $\mathrm{O}_{2}$ consumption as well as $\mathrm{CO}_{2}$ production between both phenotypes, with phenotype GO having lower values were found (Table 3 ).

Two highly influential data points, which corresponded to the first measurements of $\mathrm{O}_{2}$ consumption in each group and were assumed to be atypical, have been removed.

Based on pooled samples (four sampling days taken together for each cat), energy requirements at weight constancy for both groups was estimated with a linear regression 
approach with retained energy as independent and $\mathrm{ME}$ intake as dependent variable, additionally separately for each group. In this calculation the estimated intercept corresponds to the energy requirement at weight constancy of 246 (S.E. 22.6) kJ/BW FFM in group GL and 162.6 (S.E. 14.3) $\mathrm{kJ} / \mathrm{BW}$ FFM in group GO. The estimated mean effect on energy value of eaten diet intake of group GO compared to GL was a reduction of 83.6 (S.E. 26.4) kJ/BW FFM $(P=0.022)$. The interaction between group effect and retained energy was significant $(P=0.01)$, indicating that the association between $\mathrm{ME}$ uptake and retained energy was significantly different between the two groups. The corresponding regression coefficients (indicating the increase in $\mathrm{ME}$ uptake per one unit increase in retained energy) were 0.73 (S.E. 0.14) for group GL and 1.2 (S.E. 0.12) for group GO. If ME uptake and retained energy were referred to $\mathrm{BW}^{0.67}$, energy requirement was calculated to be 351 (S.E. 34.2 ) kJ/BW ${ }^{0.67}$ in group GL and 261 (s.e. 29.8) kJ/BW ${ }^{0.67}$ in group GO. The interaction between group effect and retained energy was not significant. The corresponding regression coefficients were 0.9 (S.E. 0.15) for group GL and 1.25 (S.E. 0.17 ) for group GO.

3.3. Food Intake Measurements. During the ad libitum feeding using the automatic feeding station, the cats of the obese phenotype $(\mathrm{GO})$ showed a significantly $(P=0.001)$ higher food intake than the cats of group GL. It corresponded to an ME intake of $422 \pm 37 \mathrm{~kJ} / \mathrm{kg} \mathrm{BW} \mathrm{BW}^{0.67}$ in group GL and $622 \pm 27 \mathrm{~kJ} / \mathrm{kg} \mathrm{BW}^{0.67}$ in group GO. Also the meal size differed significantly between the two groups, but the stay in the cat food station did not (Table 4 ). The meal frequency with $9.5 \pm 0.3$ times/24 hours in group GL and $7.2 \pm 0.2$ times/24 hours in group GO did not differ significantly $(P=0.17)$.

\section{Discussion}

In this experimental study a significant association between phenotype overweight versus lean in the following measured variables became evident: body weight and body fat, $\mathrm{O}_{2}$ consumption, $\mathrm{CO}_{2}$ production, energy requirement, food intake in $g$ and in energy value of eaten diet, and meal size, but not duration of stay or frequency. The cats of group GL showed a constant body weight during the whole study time, despite ad libitum feeding. In contrast, cats from group GO started gaining body weight soon after the beginning of ad libitum feeding. Despite similar BCS and body weight in both groups initially, group GO had a significantly lower body fat content than the animals of group GL. This could be due to a misinterpretation of abdominal skin as abdominal fat as this is one important criteria in the body condition scoring system after Laflamme [14]. At the end of the second ad libitum phase, after four weeks of weight constancy, only the cats with phenotype GO showed a significant increase in body fat, and they had a significantly higher body fat content than the cats of group GL. This difference supported the assumed different phenotypes [8] and was expected as a weight regain after a weight-loss program of overweight individuals is a known effect in pets $[20,21]$.
Although kept under similar conditions, with a similar potential for activity, the measurements taken in the respiration chamber indicate a significantly lower metabolic activity of the cats with phenotype GO compared to phenotype GL. Due to the availability of pooled samples to estimate energy requirements only one data point for each animal could be used in a linear regression approach. This potentially lowered the power to detect a significant difference between the two groups with regard to their energy requirements if referred to $\mathrm{BW}^{0.67}$. The estimated intercepts still indicate a potential higher energy requirement in group GL compared to group GO. Although not significant, the estimated regression coefficients, corresponding to the association between $\mathrm{ME}$ and retained energy, might indicate a different relationship between $\mathrm{ME}$ and retained energy in both groups. If the energy requirements were referred to fat-free body mass, a significant difference between both groups was found. This finding indicates that referring energy requirements to fat-free body mass might be more appropriate than to $\mathrm{BW}^{0.67}$. With regard to the significant difference in energy requirements between the cats of phenotype overweight and lean, it might have happened in this study design, that the weight-loss program affected the energy expenditure of the group GO, since energy restriction in cats and dogs can result in a decrease in relative energy expenditure [21-23]. The potential effect due to the weight-loss program in cats of phenotype GO might have been persisted during the following different phases explaining part of the differences found. A potential way to circumvent the potential influence of a weight-loss program would be to evaluate energy requirements earlier in life, before a distinct phenotype becomes evident (and a weight-loss program necessary to assure a similar BCS in both groups). Also a higher amount of less metabolically active fat tissue has been assumed to cause lower-energy requirements in overweight cats compared to their lean counterparts $[24,25]$. This can be excluded, however, for the cats of the present study, since the calculation of energy requirements based on fat-free mass confirmed the observed differences between the cats of the different phenotypes. It can be speculated that the difference in energy requirements also based on FFM, the possibly different relationship between $\mathrm{ME}$ and retained energy, and in $\mathrm{O}_{2}$ consumption and $\mathrm{CO}_{2}$ production were influenced by differences in activity of the cats of the two groups.

In the group GO, a significantly higher food intake either in $g$ and in terms of energy value of diet and meal size became obvious during the measurements in the automatic cat feeding station. But duration of stay or frequency was not associated with phenotype.

Increased food intake and reduced energy expenditure in cats soon after castration has been described [20, 24]. The cats in the present study were intact males in their young adulthood originating from the same cat population and reared under similar conditions. Ad libitum access to feed led to an increase in body weight and a body condition score indicative of overweight within a couple of weeks in the group predisposed to overweight but not in the normal lean group (GL). In obesity mouse models, decreased energy expenditure and increased food intake have been associated 
TABLE 4: Mean food intake, duration of single stays, food intake/min of stay, meal size, and meal frequency in the cat food station of the cats of group GL (lean phenotype) and GO (overweight phenotype), different letters show significant differences $(P<0.05)$.

\begin{tabular}{lcc}
\hline & Group GL & Group GO \\
\hline Food intake mean \pm SE $\left(\mathrm{g} \mathrm{DM} / \mathrm{kg} \mathrm{BW}\right.$ B.67 $\left.^{0} \mathrm{~d}\right)$ & $24.0 \pm 2.1^{\mathrm{A}}$ & $34.5 \pm 1.5^{\mathrm{B}}$ \\
Duration of stay mean \pm SE $(\mathrm{min} / \mathrm{d})$ & $3.3 \pm 0.2^{\mathrm{A}}$ & $4.4 \pm 0.5^{\mathrm{A}}$ \\
Food intake mean $\pm \mathrm{SE}$ g/min of stay & $2.6 \pm 0.1^{\mathrm{A}}$ & $3.7 \pm 0.1^{\mathrm{B}}$ \\
Meal Size mean \pm SE $(\mathrm{g} / \mathrm{d})$ & $8.6 \pm 0.5^{\mathrm{A}}$ & $16.6 \pm 1.8^{\mathrm{B}}$ \\
Meal frequency mean \pm SE/d & $9.5 \pm 0.3^{\mathrm{A}}$ & $7.2 \pm 0.2^{\mathrm{A}}$ \\
\hline
\end{tabular}

with mutations in the leptin system [26]. Also in obesity of humans some mutations influencing the eating behaviour are known [5, 27-30].

In humans a disordered energy balance with decreased energy expenditure and increased appetite after a weight reduction program in comparison to "normal" lean humans was observed [31]. The data of the present study support the assumption that the feeling of satiety is affected in the cats of the GO group, predisposed to overweight, since food intake, but not meal frequency or stay was significantly different between both groups. Meal frequency of all cats of the present study was in agreement with the observed frequencies by Mugford and Thorne [10], Kane et al. [11], and Peachey and Harper [12]. Because of this homogenous behaviour, rank order as cause of the differences in food intake could be excluded. This was also documented by the fact that the program did not recognize one cat of each group more often without entering the cat food station at the end. It could be concluded that the cats higher in ranking did not block the entrance of the cat food station for the other cat for a longer time. Apparently all cats followed their natural eating behaviour.

In conclusion, in the present study, the differences in food intake and energy expenditure in young intact male cats with and without predisposition to overweight could be quantified. The results indicate that in the cats showing an overweight phenotype the regulation of food intake differs from that of the "normal" lean cats. To specify the influence of energy expenditure without any weight-loss program, further investigation at earlier age in cats of the named experimental cat family is needed.

\section{Acknowledgments}

The authors thank Biomill SA for providing the cat food for the experiments. The authors also thank Ines Mittner, Barbara Schneider, and Maja Bollhalder for the laboratory analyses.

\section{References}

[1] K. Russell, R. Sabin, S. Holt, R. Bradley, and E. J. Harper, "Influence of feeding regimen on body condition in the cat," Journal of Small Animal Practice, vol. 41, no. 1, pp. 12-17, 2000.

[2] L. Colliard, B. M. Paragon, B. Lemuet, J. J. Bénet, and G. Blanchard, "Prevalence and risk factors of obesity in an urban population of healthy cats," Journal of Feline Medicine and Surgery, vol. 11, no. 2, pp. 135-140, 2009.
[3] A. J. German, "The growing problem of obesity in dogs and cats," Journal of Nutrition, vol. 136, no. 7, pp. 1940S-1946S, 2006.

[4] E. Kienzle and R. Bergler, "Human-animal relationship of owners of normal and overweight cats," Journal of Nutrition, vol. 136, no. 7, pp. 1947-1950, 2006.

[5] Y. Zhang, R. Proenca, M. Maffei, M. Barone, L. Leopold, and J. M. Friedman, "Positional cloning of the mouse obese gene and its human homologue," Nature, vol. 372, no. 6505, pp. 425432, 1994.

[6] H. H. M. Maes, M. C. Neale, and L. J. Eaves, "Genetic and environmental factors in relative body weight and human adiposity," Behavior Genetics, vol. 27, no. 4, pp. 325-351, 1997.

[7] R. J. F. Loos and C. Bouchard, "Obesity-is it a genetic disorder?” Journal of Internal Medicine, vol. 254, no. 5, pp. 401425, 2003.

[8] T. Haering, B. Wichert, G. Dolf, and B. Haase, "Segregation analysis for overweight in an experimental cat population," Journal of Heredity, vol. 102, supplement 1, pp. S28-S31, 2011.

[9] National Research Council (NRC), Nutrient requirements of Dogs and Cats, National Academic Press, Washington, DC, USA, 2006.

[10] R. A. Mugford and C. Thorne, "Comparative studies of meal patterns in pet and laboratory housed dogs and cats," in Nutrition of the Dog and Cat, R. S. Anderson, Ed., pp. 3-14, Pergamon Press, Oxford, UK, 1980.

[11] E. Kane, Q. R. Rogers, and J. G. Morris, "Feeding behavior of the cat fed laboratory and commercial diets," Nutrition Research, vol. 1, no. 5, pp. 499-507, 1981.

[12] S. E. Peachey and E. Jean Harper, "Aging does not influence feeding behavior in cats," Journal of Nutrition, vol. 132, no. 6, pp. 1735S-1739S, 2002.

[13] D. Horwitz, Y. Soulard, and A. Junien-Castagna, "The feeding behaviour of the cat," in Encyclopedia of Feline Clinical Nutrition, P. Pibot, V. Biourge, and D. Elliott, Eds., pp. 439473, Royal Canin, 2008.

[14] D. Laflamme, "Development and validation of a body condition score system for cats: a clinical tool," Feline Practice, vol. 25, no. 5-6, pp. 13-17, 1997.

[15] L. Schade, Untersuchungen zum Energiestoffwechsel von trächtigen Katzen, thesis, Zürich, Switzerland, 2006.

[16] B. Wichert, L. Schade, S. Gebert et al., "Energy and protein needs of cats for maintenance, gestation and lactation," Journal of Feline Medicine and Surgery, vol. 11, no. 10, pp. 808-815, 2009.

[17] R Development Core Team, $R$ : A language and environment for statistical computing, R Foundation for Statistical Computing, Vienna, Austria, 2010.

[18] J. Pinheiro, D. Bates, S. DebRoy, D. Sarkar, and R Core Team, "nlme: Linear and Nonlinear Mixed Effects Models," R package version 3.1-96, 2009. 
[19] A. Zeileis and T. Hothorn, "Diagnostic checking in regression relationships," R News, vol. 2, no. 3, pp. 7-10, 2002.

[20] M. L. Kanchuk, R. C. Backus, C. C. Calvert, J. G. Morris, and Q. R. Rogers, "Weight gain in gonadectomized normal and lipoprotein lipase-deficient male domestic cats results from increased food intake and not decreased energy expenditure," Journal of Nutrition, vol. 133, no. 6, pp. 1866-1874, 2003.

[21] C. Villaverde, J. J. Ramsey, A. S. Green, D. K. Asami, S. Yoo, and A. J. Fascetti, "Energy restriction results in a mass-adjusted decrease in energy expenditure in cats that is maintained after weight regain," Journal of Nutrition, vol. 138, no. 5, pp. 856860, 2008.

[22] J. J. Ramsey and K. Hagopian, "Energy expenditure and restriction of energy intake: could energy restriction alter energy expenditure in companion animals?" Journal of Nutrition, vol. 136, no. 7, pp. 1958S-1966S, 2006.

[23] D. Nagaoka, Y. Mitsuhashi, R. Angell, K. E. Bigley, and J. E. Bauer, "Re-induction of obese body weight occurs more rapidly and at lower caloric intake in beagles," Journal of Animal Physiology and Animal Nutrition, vol. 94, no. 3, pp. 287292, 2010.

[24] M. J. Fettman, C. A. Stanton, L. L. Banks et al., "Effects of neutering on body weight, metabolic rate and glucose tolerance of domestic cats," Research in Veterinary Science, vol. 62, no. 2, pp. 131-136, 1997.

[25] E. Kienzle, G. Edtstadtler-Pietsch, and R. Rudnick, "Retrospective study on the energy requirements of adult colony cats," Journal of Nutrition, vol. 136, no. 7, pp. 1973S-1975S, 2006.

[26] P. Magni, M. Motta, and L. Martini, "Leptin: a possible link between food intake, energy expenditure, and reproductive function," Regulatory Peptides, vol. 92, no. 1-3, pp. 51-56, 2000.

[27] L. A. Tartaglia, M. Dembski, X. Weng et al., "Identification and expression cloning of a leptin receptor, OB-R," Cell, vol. 83, no. 7, pp. 1263-1271, 1995.

[28] K. S. Graham and R. L. Leibel, "Yellow mice, red hair, and childhood obesity: the melanocortinergic pathway in energy homeostasis," Journal of Pediatrics, vol. 139, no. 2, pp. 177$181,2001$.

[29] S. Carnell, C. M. A. Haworth, R. Plomin, and J. Wardle, "Genetic influence on appetite in children," International Journal of Obesity, vol. 32, no. 10, pp. 1468-1473, 2008.

[30] W. F. Mathes, S. A. Kelly, and D. Pomp, "Advances in comparative genetics: influence of genetics on obesity," British Journal of Nutrition, vol. 106, pp. S1-S10, 2011.

[31] M.-A. Cornier, "Is your brain to blame for weight regain?" Physiology and Behavior, vol. 104, no. 4, pp. 608-612, 2011. 


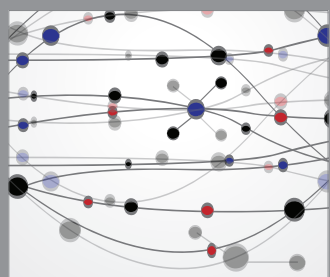

The Scientific World Journal
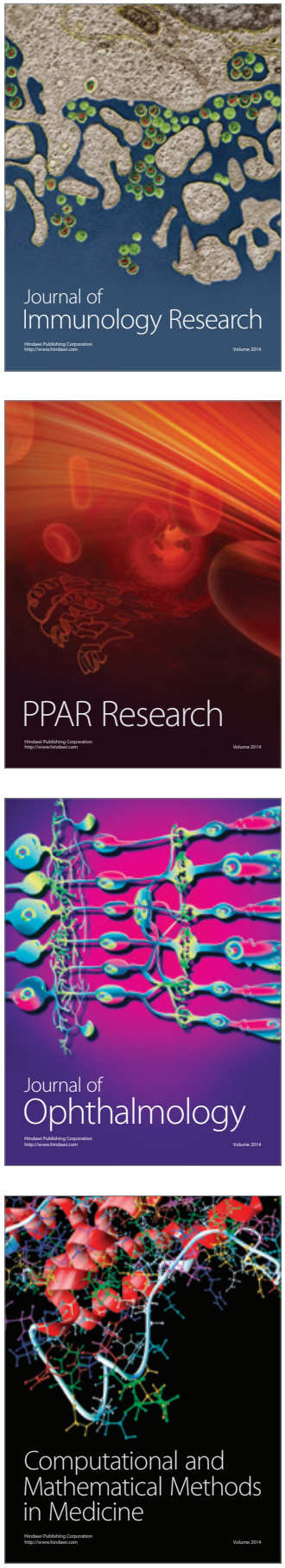

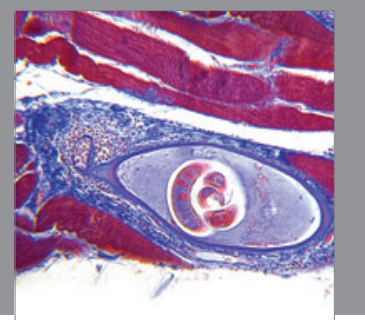

Gastroenterology

Research and Practice
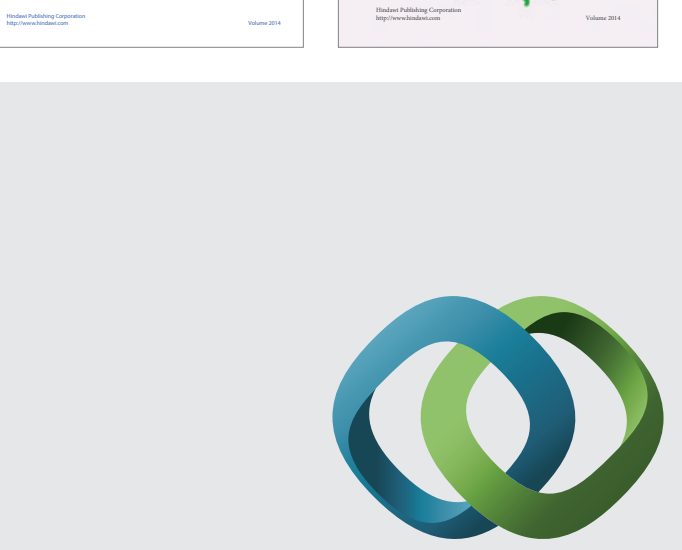

\section{Hindawi}

Submit your manuscripts at

http://www.hindawi.com
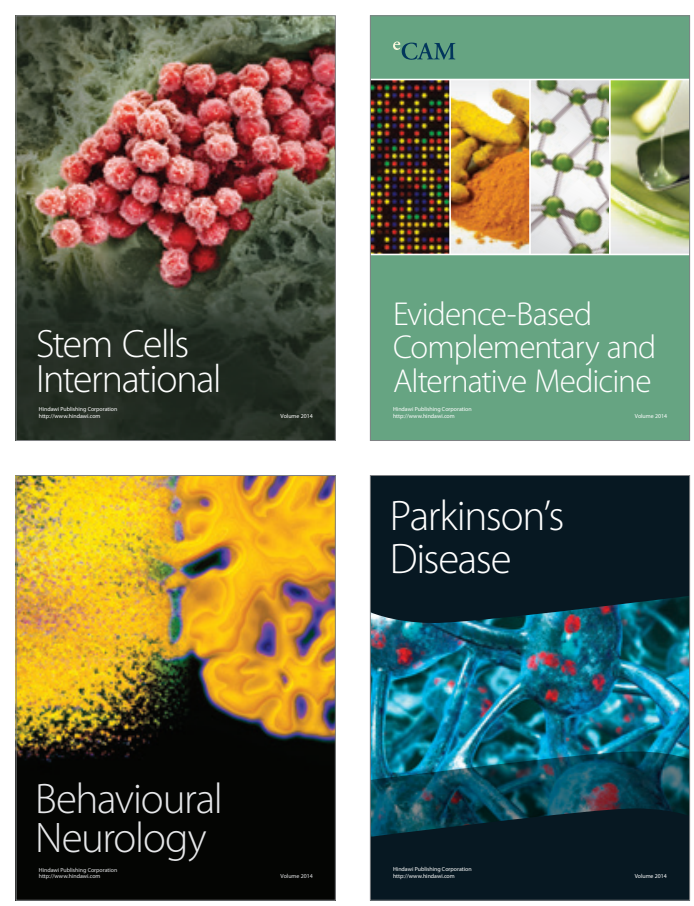

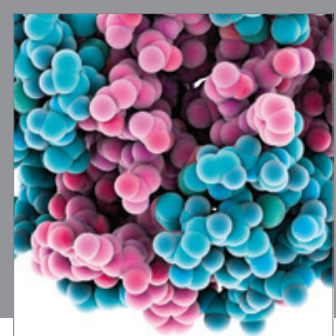

Journal of
Diabetes Research

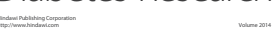

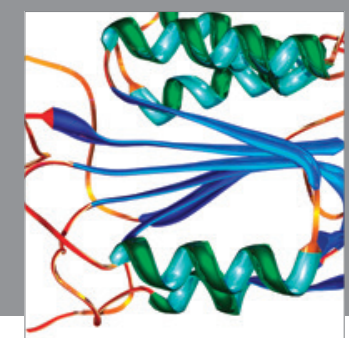

Disease Markers
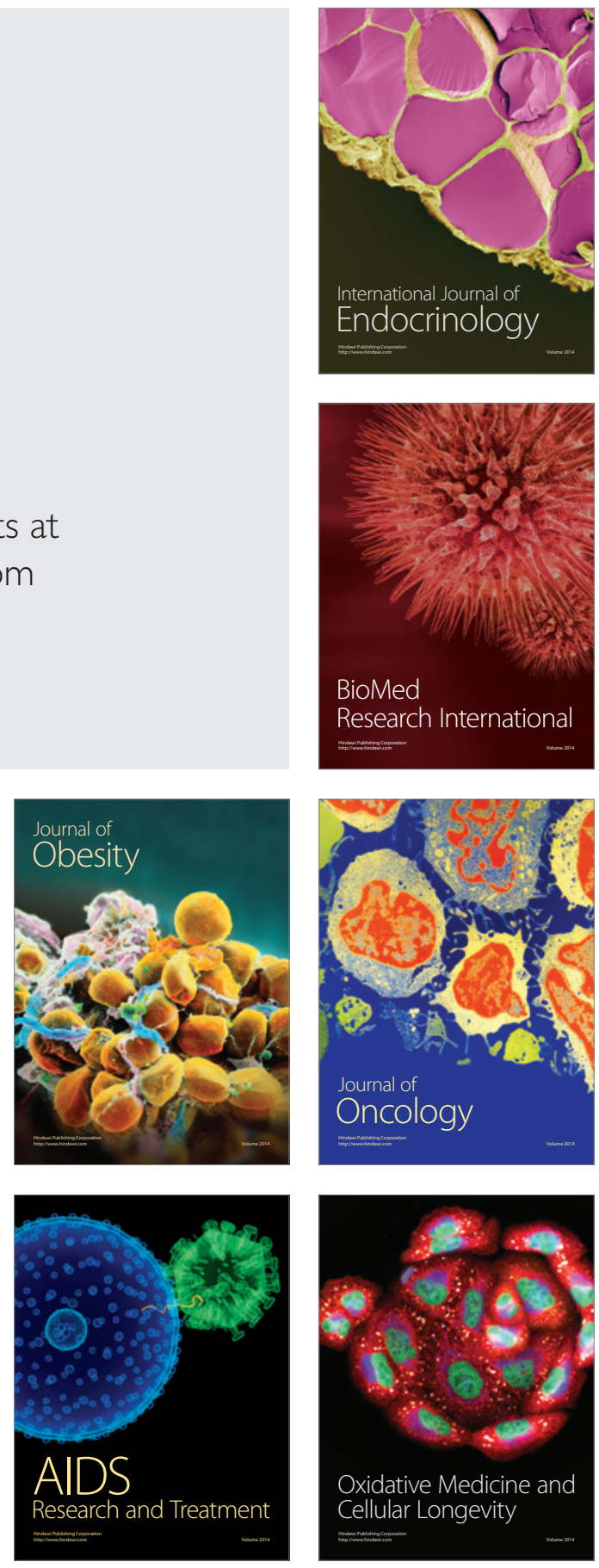